\title{
EFFECT OF SPARK ADVANCE ON A GAS RUN AUTOMOTIVE SPARK IGNITION ENGINE
}

\author{
Md. Ehsan* \\ Department of Mechanical Engineering \\ Bangladesh University of Engineering and Technology, Dhaka 1000, Bangladesh
}

\begin{abstract}
Petrol engines can run on natural gas, with little modification. The combustion characteristics of natural gas is different from that of petrol, which eventually affects the engine performance. The performance of a typical automotive engine was studied running on natural gas, firstly at a constant speed for various loads and then at a constant load for a range of speeds and results were compared with performance using petrol. Variation of the spark advance, consisting of centrifugal and vacuum advance mechanisms, was investigated. Results showed some reduction in power and slight fall of efficiency and higher exhaust temperature, for natural gas. The air-fuel ratio for optimum performance was higher for gas than for petrol. This variation in spark requirement is mainly due to the slower speed of flame propagation for natural gas. For both the cases, the best power spark advance for natural gas was found to have higher values than petrol. This issue needs to be addressed during retrofitting petrol engines for running on natural gas.
\end{abstract}

\section{Introduction}

The sharp rise of conventional fossil fuel price is creating a huge effect on world economy. The issue of environmental pollution created by conventional fossil fuels is becoming more important, as we are getting more concern about the environment of our planet. These concerns as well as emission standards enforced by legislation, have led the research for the use of alternative fuels in different prime movers, including the extensively used internal combustion engines. Fuels, which have been studied for replacing petrol include - natural gas, compressed natural gas (CNG), liquefied petroleum gas (LPG), hydrogen, bio-gas etc ${ }^{1}$. Each of these has its merits and demerits for its use in different application. Among these alternative fuels, natural gas is attracting significant attention at present time. It is low in pollutants, high in calorific value, economical and available in abundance globally. Pollution level from the engine could be drastically reduced using natural gas ${ }^{2}$. Unlike liquid petroleum reserves, natural gas is widely distributed around the world with substantially large reserves already discovered in most of the regions ${ }^{3}$. At the present time, the availability of natural gas, relative simplicity of engine conversion technology, economical and environmental benefits and in some cases strategic advantage makes it the preferred fuel ${ }^{4}$.

\section{CNG as an Alternative Fuel for Internal Combustion Engines}

Compressed Natural Gas (CNG) is one of the most promising alternatives to traditional fuel energy resources for internal combustion engines of various types. Over two million natural gas vehicles (NGV) are in operation worldwide. Natural gas available in Bangladesh has very high methane content (94-98\%). The Auto-ignition temperature, Octane rating and Calorific value of methane is much better for use in internal combustion engines compared to gasoline. Table 1 shows the comparison of some relevant properties of methane, gasoline and diesel ${ }^{1,5}$. Natural gas being a gaseous fuel at normal atmospheric conditions has the inherent advantage of high level of miscibility and diffusion with gaseous air, which is essential for good combustion. On the other hand lot of development of the engine fuel system have been dedicated to proper mixing of conventional liquid fuel with gaseous air in modern internal combustion engines. As a result use of $\mathrm{CNG}$ in more conventional engines like those using carburetor and older versions of electronic fuel injection system results drastic improvement in exhaust emissions. The emission improvements are less dramatic for engines with sophisticated closed loop fuel supply systems and post engine emission control devices. CNG conversion technology itself is also going through developments - from open loop without active gas flow towards close-loop active gas flow control and ultimately electronic control of gas injection. Although the emission control and environmental aspects of using CNG was the prime consideration of CNG application in internal combustion engines, especially inside big cities, in recent days with sharp increase in oil prices, the increasingly significant economic advantage of using $\mathrm{CNG}$ has become the real prime consideration for lot of new users.

Table 1: Comparison of typical values of some related properties of three fuels.

* Corresponding author's e-mail: ehsan@me.buet.ac.bd 


\begin{tabular}{|c|c|c|c|}
\hline Property & $\begin{array}{l}\text { Natural } \\
\text { gas } \\
\text { (Methane) }\end{array}$ & Gasoline & Diesel \\
\hline Formula & $\mathrm{CH}_{4}$ & $\mathrm{C}_{4}-\mathrm{C}_{12}$ & $\mathrm{C}_{8}-\mathrm{C}_{25}$ \\
\hline $\begin{array}{l}\text { H-Content } \\
\text { \%weight }\end{array}$ & 25 & $12-15$ & $13-16$ \\
\hline $\begin{array}{l}\text { Density } \mathrm{kg} / \mathrm{m}^{3} \\
\text { (Ambient, } 25^{\circ} \mathrm{C} \text { ) }\end{array}$ & 0.66 & 730 & 840 \\
\hline $\begin{array}{l}\text { Vapour density, } \\
\text { compared to air }\end{array}$ & Lighter & Heavier & Heavier \\
\hline $\begin{array}{l}\text { Boiling point } \\
\text { Temp }{ }^{\circ} \mathrm{C} \text {, atmp }\end{array}$ & -162 & $27-225$ & $\begin{array}{l}188- \\
343\end{array}$ \\
\hline $\begin{array}{l}\text { Latent heat of } \\
\text { vaporization } \\
\mathrm{kJ} / \mathrm{kg} \text { (Ambient, } \\
25^{\circ} \mathrm{C} \text { ) }\end{array}$ & - & 349 & 233 \\
\hline $\begin{array}{l}\text { Flash point } \\
\text { temperature }{ }^{\circ} \mathrm{C}\end{array}$ & -188 & -43 & 74 \\
\hline $\begin{array}{l}\text { Auto Ignition } \\
\text { (SIT) } \\
\text { temperature }{ }^{\circ} \mathrm{C}\end{array}$ & 540 & 257 & 316 \\
\hline $\begin{array}{l}\text { Octane/Cetane } \\
\text { Number }\end{array}$ & 120 & $90-100$ & $40-55$ \\
\hline $\begin{array}{l}\text { Flammability } \\
\text { limit, Vol\% }\end{array}$ & $5-15$ & $1.4-7.6$ & $1-6$ \\
\hline $\begin{array}{l}\text { Flammability } \\
\text { limit, AF ratio } \\
\text { (mass) }\end{array}$ & $34.3-10.2$ & $25-4$ & - \\
\hline $\begin{array}{l}\text { AF ratio, } \\
\text { Stoichiometric } \\
\text { (mass) }\end{array}$ & 17.2 & 14.7 & 14.7 \\
\hline $\begin{array}{l}\text { Flame } \\
\text { propagation } \\
\text { Speed } \mathrm{m} / \mathrm{s}\end{array}$ & 0.43 & 0.5 & - \\
\hline $\begin{array}{l}\text { Common } \\
\text { Compression } \\
\text { ratio }\end{array}$ & $9-12$ & $9-12$ & $16-24$ \\
\hline $\begin{array}{ll}\text { Lower } & \text { Heating } \\
\text { value } & \mathrm{MJ} / \mathrm{kg} \\
& \mathrm{MJ} / \mathrm{liter} \\
\end{array}$ & $\begin{array}{l}50 \\
0.033 \\
\end{array}$ & $\begin{array}{l}44 \\
32 \\
\end{array}$ & $\begin{array}{l}42 \\
36 \\
\end{array}$ \\
\hline
\end{tabular}

\section{CNG Technology}

Natural gas can be readily used in the spark ignition (SI) engines without major modification to the engine structure, retaining the option of easy switchability back to gasoline. So retrofitting/conversion of these engines are most suitable for use of $\mathrm{NG} / \mathrm{CNG}$ and popular in automotive applications. For using CNG in automotive applications two pre-requisites have to be ensured. Firstly to convert/modify the existing engine so it can run with natural gas. This requires pressure reduction of high pressure $\mathrm{CNG}$ in cylinders in order to introduce it into the engine and control its flow with engine requirements. Secondly a fuel compressing, storing and dispensing system that will allow transportation of the gas under high pressure to overcome the low power density of natural gas and allow it to be used in mobile applications. For stationary engines a more simple system using a line supply of natural gas may be used

\section{CNG Conversion Components}

A typical standard CNG conversion (retrofit) system essentially consists of the following ${ }^{5}$, the locations are indicated in fig. 1 .

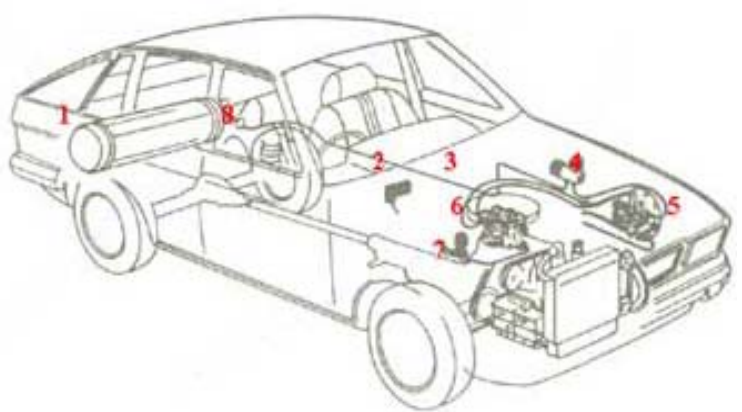

Fig. 1: CNG conversion components of a vehicle

1. The Cylinder is used to store $\mathrm{CNG}$ at a working pressure of 200 bar. It is fitted with a shut-off valve and a safety burst disc. Cylinders may be of seamless steel structure or reinforced carbon fiber composite. 50, 60, 90 water liter size cylinders are commonly used. At a pressure of 200 bar and ambient temperature $\mathrm{CNG}$ is compressed to about 3.7 times of equivalent petrol volume 5 . Due to the cylindrical shape and wall thickness the packing efficiency is poor and the real car space blocked by the cylinders is much more. The shut-off valve with the cylinder may have overflow limiter facilities built-in.

2. The selector Switch is fitted at the dash board, enabling the driver to choose either the CNG mode or the petrol mode of operation. The electronics built in this unit also ensures safety by switching off the gas solenoid whenever the engine is switched off. It also indicates the quantity of CNG available in the cylinder.

3. The High Pressure Pipe connects the refueling valve to the $\mathrm{CNG}$ Cylinder and Pressure Regulator.

4. The Refueling Valve is used to refuel the CNG cylinder.

5. The Pressure Regulator has a solenoid valve to shut-off gas supply to the engine. The $\mathrm{CNG}$ stored at a high pressure in the cylinder, is reduced to just below atmospheric pressure by this unit. This negative pressure is also a safety 
feature that will not allow gas to pass through when the engine is not running. Generally this is provided with a gas filter element.

6. The Gas- Air Mixer is a unique component, specially designed to suit each engine model. It precisely meters gas fed into the engine.

7. Petrol Solenoid valve is used to cut off petrol supply to the engine when it is run on CNG.

8. Fitted near the cylinder, the Vapour bag/enclosure is used to enclose the cylinder valve and the pipes connecting it and is vented out of the car.

In addition to these basic components the conversion system may have few more components, generally if the engine is equipped electronic fuel injection system and electronic control unit (ECU). These include the following:

Spark Timing Advance Processor (STAP/TAP): The slower flame propagation speed in methane-air mixture make it necessary to increase the spark advance for CNG operation of a petrol engine ${ }^{1,6}$. This unit allows optional spark advances (e.g. additional 6, $9,12,15^{\circ}$ BTDC), generally during accelerating conditions. The processor modifies the spark advance signal to the electronic ignition system accordingly. Use of this improves the peak power and acceleration performance of the vehicle running on $\mathrm{CNG}$, while retaining the performance with petrol.

Emulator/Simulator: The EFI injectors are generally kept non-functional at CNG operation. On the other hand, in some engines feedback signals from the fuel injectors operation is fed back to the electronic control units (ECU). Under $\mathrm{CNG}$ operation the emulator simulates dummy feedback signals to the ECU, maintaining its normal operation as with petrol. This component may not be necessary for all models of EFI engines.

Oxygen Sensors and Speed sensors: Often these are required in close-loop gas flow-control $\mathrm{CNG}$ conversion systems.

Active Mixing Valve : Controls the flow of gas into the mixing chamber according to engine requirements sensed.

Gas Injectors : These are used for conversion systems, where just like multipoint fuel injection system, individual gas injectors control gas flow into each cylinder controlled by a processor unit.

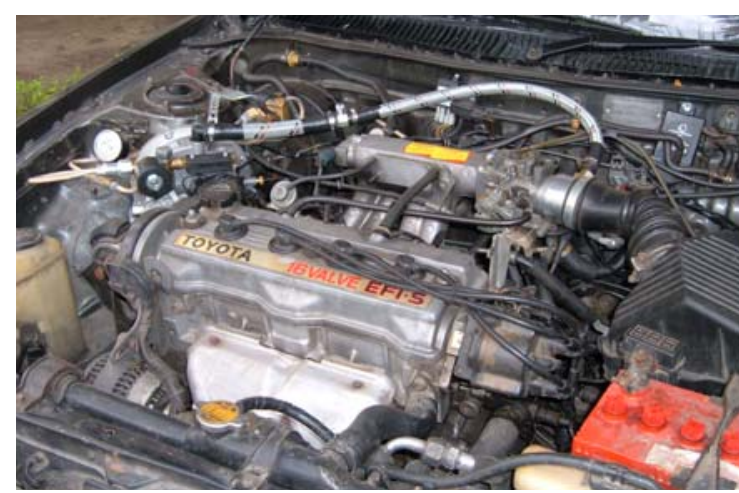

Fig. 2: CNG conversion components fitted on a typical automotive engine.

From the storage tank up to the pressure regulator the CNG conversion components are almost similar for all the systems. In the most conventional conversion systems, used with carburetor engines, the spark advance is manually adjusted to an optimum position for $\mathrm{CNG}$ but compromises performance running on petrol. In open-loop CNG systems the STAP/TAP is used making the manual adjustment of spark advance unnecessary. This improves the acceleration performance while retaining most of the performance while running with petrol. In both the category stated above the gas flow is not actively controlled with engine speed and load requirements, it changes indirectly through the variation of intake manifold vacuum and hence cannot be fully optimized for both the fuels. During CNG operation the petrol flow is cutoff by deactivating the fuel pump or signal to the injectors through relay switches. In more advanced conversion kits a closed loop system is used where sensors like oxygen/lambda sensors are used to actively control the gas flow rate according to the engine requirement. In conversions using gas injections the CNG gas flow is controlled by a system almost parallel to the existing EFI fuel supply system running for petrol.

CNG being an indigenous fuel, using it replaces imported petrol and diesel, saving lot of foreign currency and dependency on other countries. CNG being a clean gaseous fuel is capable of reducing engine emissions significantly if properly used. Bangladesh is correctly trying to make use of its indigenous fuel source in internal combustion engines of various categories. The world wide rise of oil prices has provided the very effective economic incentive to get this technology established. CNG being a technology dealing with high gaseous fluid pressure, the safety issues related to it is of prime public interest worldwide. 

Effect of Spark Advance for Using Natural Gas in
a Typical Automotive SI Engine

\section{The Experimental Setup}

A typical 4-stroke, 4-cylinder, Inline, Water cooled automotive engine was run with natural gas. The Carburetor car engine with $1600 \mathrm{cc}$ displacement volume, Mechanical Contact Breaker ignition and a Compression ratio of 9 had a rated power of $33 \mathrm{~kW}$ and speed range of 700-3600 rpm. The absence of electronic control on the fuel flow and spark timing allowed independent manual adjustment of these parameters.

This research work involved a detailed study of effect of variation of spark advance on the performance of the engine run on natural gas. In the study two approaches were adopted. In the first approach the engine was tested at varying speeds $(1025,1200,1500,1700,2000$, 2200, 2500, and $2700 \mathrm{rev} / \mathrm{min}$ ) keeping the load constant $(15 \mathrm{~kg})$ running on petrol. For petrol at each speed the variation of power was measured using the dynamometer and tachometer readings, at various spark advance settings. The variation of speed and load was controlled by the throttle valve control mechanism. The spark advance positions were changed manually. The spark advance position at which best power is attained, is known as the best power spark advance (bpsa). At each bpsa condition the fuel flow rate, exhaust temperature, cooling water temperature, manometer reading for air flow rate and intake manifold vacuum were recorded. The same procedure was followed for the engine when running with natural gas at various speeds $(1025,1200,1500,2000,2500 \mathrm{rev} / \mathrm{min}$, at load of $15 \mathrm{~kg})$. In this case the load and speed was controlled by the simultaneous adjustment of the gas flow control valve and the throttle position. For natural gas, a rotameter was used to measure the gas flow rate. The rotameter was calibrated prior to the experiment.

In the second approach the speed was kept constant at $2500 \mathrm{rev} / \mathrm{min}$. For petrol the readings similar to the first approach were taken, but this time at variable loads (at $18,19,20,21,22,23,24$ and $25 \mathrm{~kg}$ ) keeping the speed constant $(2500 \mathrm{rev} / \mathrm{min})$. Also for natural gas readings similar to the first approach were taken at the best power spark advance positions for variable loads (at 15, $17,18,19,20,21,22,23$ and $24 \mathrm{~kg}$ loads at 2500 $\mathrm{rev} / \mathrm{min})$. Similar to the first approach natural gas needed simultaneous adjustment of gas flow control valve and throttle control mechanism.

A water-brake type hydraulic dynamometer (model no. TFJ-250L) was used to measure the engine performance. Three separate metering systems were used to measure the flow rates of air, petrol and natural gas. The acceleration paddle (throttle valve) control mechanism of the engine was replaced by linear motion of a spring-locked screw mechanism. An air drum fitted with a parabolic nozzle and inclined manometer was used for measuring the mass flow of the air entering the engine. A cross flow-mixing box was used to introduce line supply of natural gas in to the intake air ${ }^{7,8}$. Type-K thermocouples were used for temperature measurements of the cooling water, lubricating oil and engine exhaust. Relevant test results were de-rated as per BS5514.

The spark advance measuring mechanism consisted of a high voltage electric bulb, cord connections and a light-reflecting marker. The high surge carrying electric cord from the distributor, which is aimed for no. 1 cylinder of the engine, was connected to the input cord of the special electric bulb. The output cord

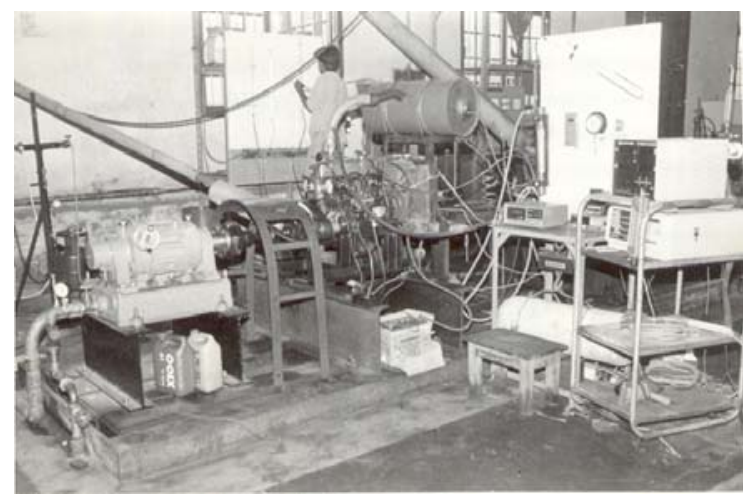

Fig. 3: Photograph of the engine test bed.

of the electric bulb was connected to the spark plug of the first cylinder (firing order 1-3-4-2). Each time a high voltage surge from the ignition coil passes through this connecting system, the bulb blinks. A light-reflecting marker was placed on the flywheel plate indicating the TDC of the first cylinder. A stationary scale was placed on the engine body (as in Fig. 4), which shows the angle in degrees before top dead center (btdc). Each time a high voltage surge passes through the circuit, the lamp blinks and the reflector becomes visible. The relative position of the reflector marker with respect to the stationary scale indicates the angle at which the spark occurs before the piston reaches the TDC. The mechanism used as shown in figure-4, is similar to a stroboscope in operation $^{8}$. The spark advance positions were changed by manual adjustment of the distributor unit. In this process the position of the contact breaker plate was changed relative to the distributor casing, causing the spark advance to change with respect to the TDC. 

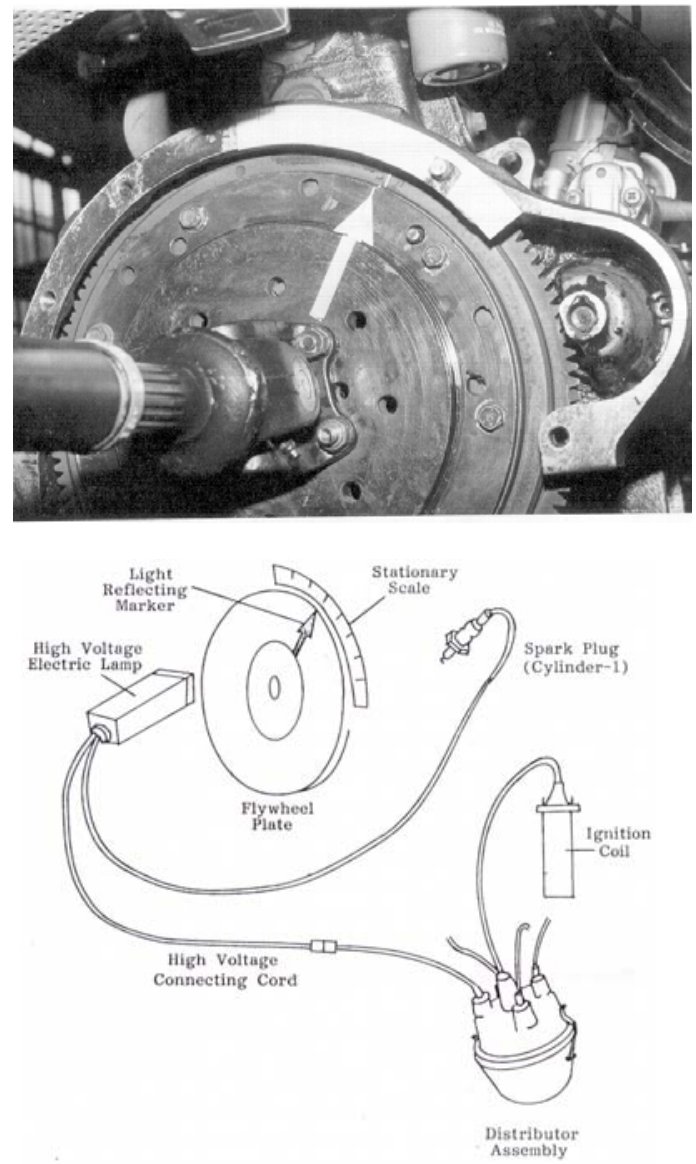

Fig. 4: Photograph of the spark advance measurement system.

\section{Results and Discussion}

In the first approach the best spark advance was found for engine running at various load conditions, but at a constant speed with both fuels. Since the speed is constant $(2500 \mathrm{rev} / \mathrm{min})$, for both the fuels, the effect of the centrifugal advance mechanism is the same. Therefore the required variation of spark advance for best power has to be done with the vacuum advance mechanism. Fig. 5 shows the variation of air flow rate at various loads at 2500 $\mathrm{rev} / \mathrm{min}$, for both petrol and natural gas. At higher load the throttle opening is wider, more fuel enters the engine and more air is needed for its combustion. The curve for natural gas has higher values than that of petrol. This indicates that greater amount of air is needed for combustion of natural gas, than petrol fuel. So for natural gas the throttle position had to be opened more, even for the same load. At loads higher than $22 \mathrm{~kg}$, for natural gas the airflow was almost constant, which indicates that the extreme limit of the throttle position for the petrol engine had been reached. The spark advance needed for natural gas is much higher than that of petrol, while the vacuum effect created in the intake manifold is less for natural gas, so further increase of spark advance was done manually to get the best power with natural gas ${ }^{4,7,8}$. Fig. 5 shows the variation of $\mathrm{A} / \mathrm{F}$ ratio and variation of the intake manifold vacuum, which is weaker for NG as the gas occupies more volume. Because of limitation of air intake as gas occupies more volume the maximum engine power $(17.9 \mathrm{~kW})$ running with natural gas is less than when running with petrol fuel $(19.7 \mathrm{~kW})$. The minimum equivalent bsfc found for natural gas was found to be slightly higher $(1.7 \%)$ than the minimum bsfc for petrol fuel. This is mainly caused by the slower flame propagation speed of natural gas. The slower burning rate allows exit of a greater amount of unburned natural gas through the exhaust. In case of petrol, the fuel enters the carburetor in the form of fine liquid along with air. By the time the charge enters the cylinder the liquid particles become almost completely vaporized this increases the inlet pressure of the cycle. In case of natural gas, the fuel supplied is gaseous; hence such increase in inlet pressure is not present. These two factors most likely cause the slight rise of the bsfc (347 $\mathrm{g} / \mathrm{kW}$-h for petrol and $353 \mathrm{~g} / \mathrm{kW}$-h equivalent for natural gas, at rated load) and fall of brake thermal efficiency $(23.6 \%$ for petrol and $23.1 \%$ for natural gas). Fig.6 shows the variation of exhaust temperatures with load for both petrol and natural gas. At all loads the exhaust temperature is higher for natural gas than petrol fuel. The flame speed of natural gas is less than that of petrol. Therefore, burning of the air gas mixture continues well in the expansion stroke, which causes the exhaust temperature to rise. The spark advance requirement for natural gas is 15-20 degrees more compared to petrol for best power' ${ }^{9}$. In both cases as the throttle opens up at higher loads the advance requirement decreases.

In the second approach the load was kept constant while the engine speed was varied. Similar experiments were carried out first using petrol and then natural gas as the fuel. Fig.7 shows the Air flow rate, AFratio and Intake manifold Vacuum at different speed varied between 100-2700 rpm at constant load. The centrifugal advance mechanism plays the main role in changing the spark advance at different speeds. Although load is unchanged for both the fuels, but since the throttle valve needs relatively larger opening and the intake manifold vacuum is weaker with gas some motion of vacuum advance mechanism occurs in parallel. 

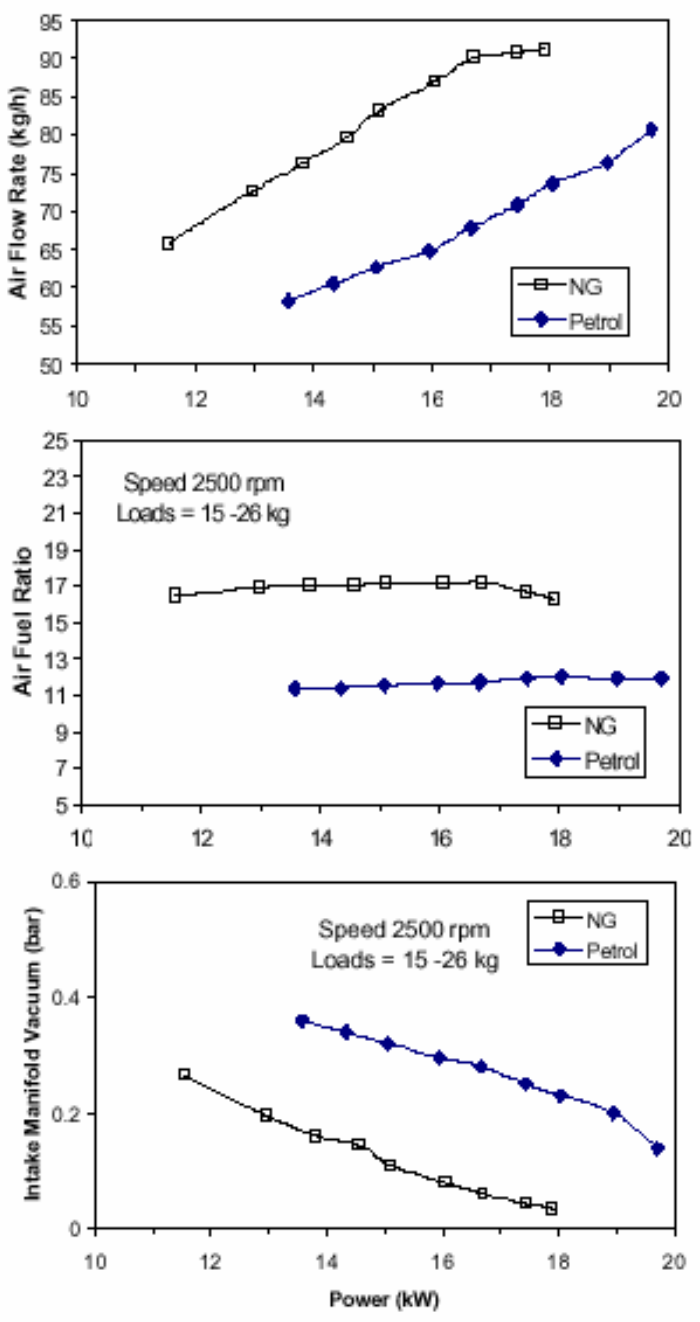

Fig. 5: Variation of Air flow, AF ratio and Intake Manifold Vacuum for petrol and natural gas. Tests are carried out at variable loads and at a speed of $2500 \mathrm{rpm}$.

At speeds of $1000,1250,1500,2000$ and 2500 $\mathrm{rev} / \mathrm{min}$ the spark advances were recorded along with fixed load for natural gas. At each of these speeds, spark advance and air-gas ratio were manually changed to get best possible power. The data recorded at various speeds, with different spark advances are shown in Fig. 8 the best power spark advances (bpsa) were determined. The requirement is almost linearly proportional to engine speed for both natural gas and petrol, but with different slopes. For the engine, spark advance needed for best power at any speed is higher (about 12-15 degrees BTDC) for gas compared to petrol fuel. This mainly is caused by the lower flame
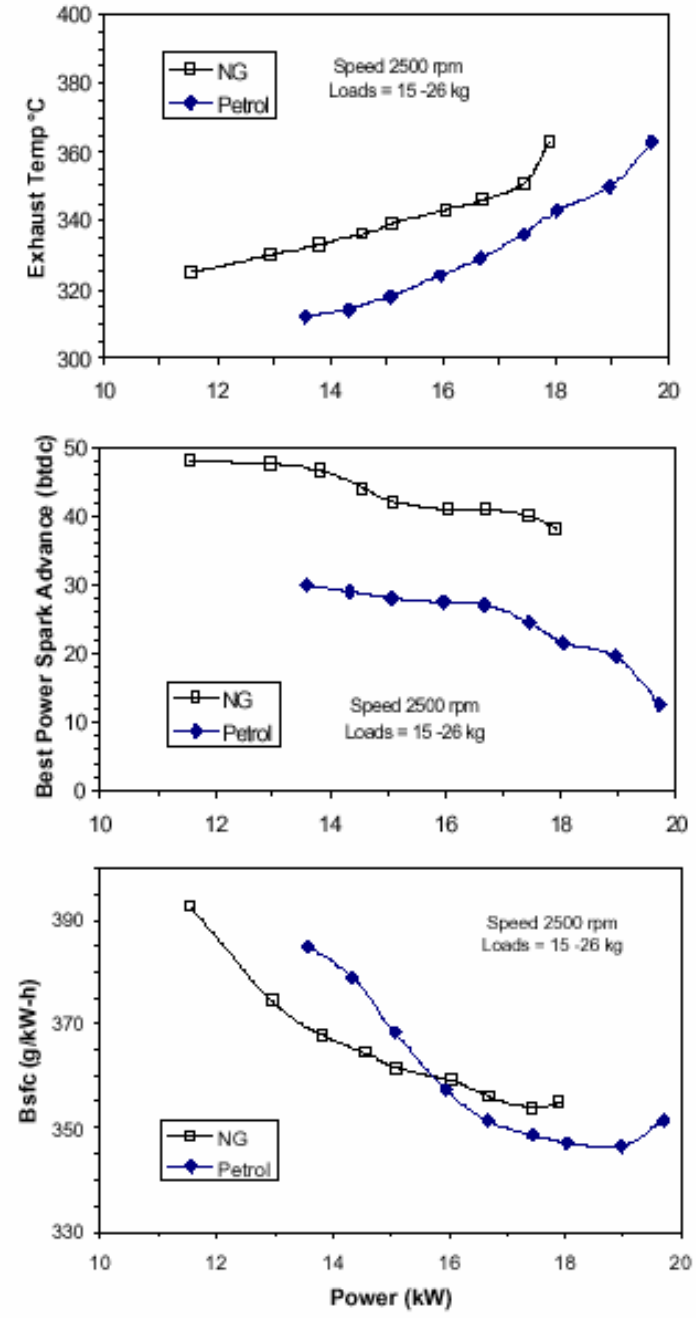

Fig. 6: Variation of Exhaust temperature, Best power Spark Advance and Equivalent Bsfc for both fuels

speed of natural gas compared to petrol ${ }^{10,11}$. The minimum equivalent bsfc with gas was better for low powers, but reaching only slight improvement to 406 $\mathrm{g} / \mathrm{kWh}$ (about 21\% efficient) compared to petrol (411 $\mathrm{g} / \mathrm{kWh}$ ), at higher power. The maximum power produced was limited to $11.4 \mathrm{~kW}$ with gas compared to $12.1 \mathrm{~kW}$ with petrol. 

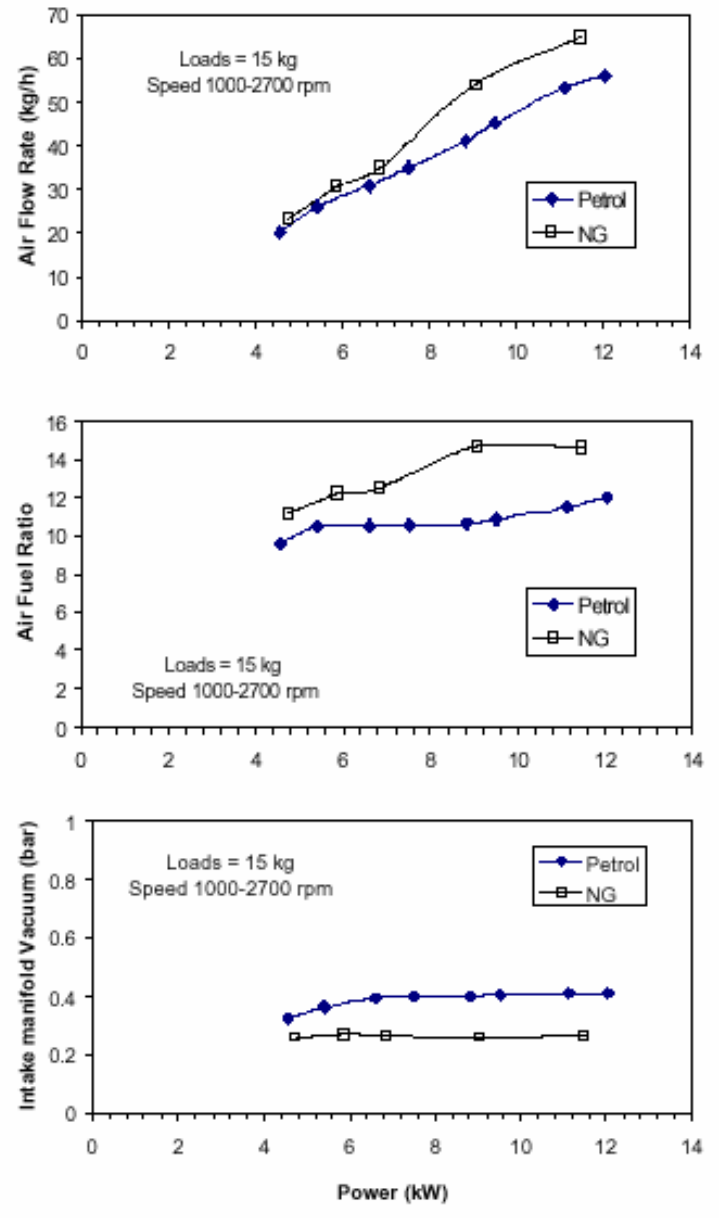

Fig.7: Variation of Air flow, AF ratio and Intake Manifold Vacuum for petrol and natural gas. Tests are carried out at constant load and at a speeds varying from 1000 to $2700 \mathrm{rpm}$.

\section{Conclusions}

For running a retrofitted petrol engine efficiently with natural gas, few limitations need to be recognized and a number features need to be incorporated in the conversion system. In case of a dedicated gas engine these probably would already have been addressed by the manufacturer.

- $\quad$ The maximum automotive engine power produced when running on natural gas will be lower (in the order of about 5-10\%) compared to when running on petrol. This should not have very visible effect during normal cruise of a vehicle. However it may increase the time taken by the vehicle to accelerate when operating under full load conditions.
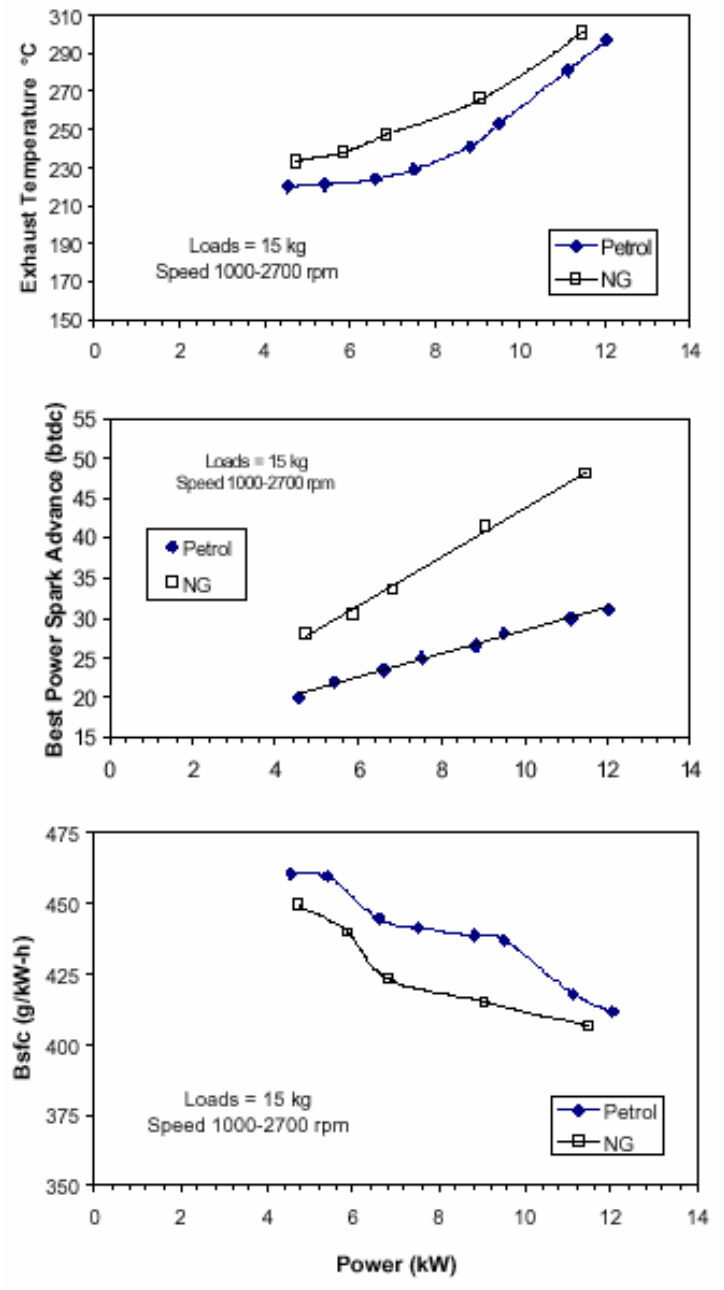

Fig. 8: Variation of Exhaust temperature, Best power Spark Advance and Equivalent Bsfc for both fuels

- $\quad$ The gas flow rate needs to be adjusted according to the engine operating conditions to attain the required air-fuel ratio. It should be noted that the gas flow practically by-passes the carburetor details or the sophisticated electronic fuel injection system but being gaseous has the inherent advantage of far better miscibility with incoming air. Even an optimized passive flow control device will be altering gas flow close to the required level as the intake vacuum changes, under some operating conditions. For better performance through out the power range, active flow control devices (eg. close loop flow control using $\mathrm{O}_{2}$ sensor, electronically controlled Gas injection etc.) may be used. 
- $\quad$ Many engines use intake manifold vacuum signal as an important parameter, for controlling different engine function (eg, vacuum advance of spark, throttle positioning, fuel enrichment etc.). In the same manifold structure when gaseous fuel is introduced it weakens the vacuum created by suction process (due to the larger volume occupied by gas) compared to petrol. If this is not taken into account, it may result in improper adjustment of the support features (eg. vacuum advance) of the engine hampering the engine performance. Producing same power requires more throttle opening.

- $\quad$ The speed dependent spark advance (centrifugal) requirement is much higher for natural gas compared to petrol. The requirement also changes at a different rate with speed compared to petrol. In engines with ECU and electronic ignition system this can be addressed by using a spark advance processor (STAP/TAP), correcting the spark advancement signal when using natural gas especially during engine acceleration. More conventional engines go for a fixed manual advancement optimized for running on gas but have to compromise performance when running on petrol.

- The higher hydrogen contents allow the maximum temperature of combustion to be higher in case of a gas run engine. On the other hand the temperature of exhaust gas is a function of power produced. As the peak power is a little bit limited, the maximum temperature attained may not be significantly higher in comparison to petrol operation, but at part loads the engine experiences higher temperature (in the order of $20-35^{\circ} \mathrm{C}$ in this case) in exhaust path. This also may cause some overheating specially in old vehicles where the cooling performance of the radiator was already limited.

\section{Acknowledgement}

Department of Mechanical Engg, BUET provided the funding for the research work.

\section{References}

1. Goodger, E. M., “Alternative Fuel”, Macmillan Press Ltd., ISBN-0-333-25813-4, U. K., 1980.

2. Karim, G. A. and Ali, A. I., "Combustion, Knock and Emission Characteristics of a Natural Gas Fuelled Spark Ignition Engine with Particular Refference to Low Intake Temperature Conditions", Proc. Mech. Engrs. Vol: 189, 24/75, 1975.

4. C R Stone, K J S Mendis, and M Daragheh, "Measurements and Modelling of a Lean Burn Gas Engine". Proc. I Mech E Vol 210 Part A6, pp 449-462, London, 1996.

5. Bechtold R. L., "Alternative Fuels Guide Book", SAE International Publication, ISBN 0-76800052-1, Warrandale, PA, USA,1997.

6. Bell A., Stuart R., "Natural Gas as Transportation Fuel", SAE Technical Paper No.931829, pp. 29-35, Warrendale PA, USA 1993.

7. Ehsan Md. and Alam M. S.B., "Effect of Independent Gas Flow Control on the Performance of a Fixed-Speed Gas Run SI Engine", accepted paper No. JMED-128, ME 33, Journal of Mechanical Engineering, Institution of Engineers Bangladesh (IEB), pp. 1-11, June \& Dec 2004 Vol. ME 33.

8. Ehsan, M., "Study of the effect of Spark Advance on Gas run Petrol Engine." M. Sc. Engg. Thesis, BUET, Dhaka Bangladesh, 1993.

9. Bell, S. R., Loper, G. A., Gupta, M., "Combustion Characteristics of a Natural Gas fuelled Spark Ignition Engine”, ASME Paper 93ICE-17, 1993.

10. Maly, R., and Vogel, M., "Ignition and Propagation of Flame Fronts in Lean $\mathrm{CH}_{4}$-Air Mixture by three modes of Spark Ignition", Proceedings of the $17^{\text {th }}$ international Symposium on Combustion, pp. 821-831, The Combustion Institute, 1986.

11. A Spencer, R Stone, E P Lim and S Simonini, "Combustion Performance of Methane, Isooctane, Toluene and Methanol in a Spark Ignition Engine", Journal of Institute of Energy, Vol 72, pp 157-164, Dec 1999. 